\title{
A PROFIT ANALYSIS OF SMALL-SCALE MAIZE FARMERS: A CASE STUDY IN THE BRONG AHAFO REGION OF GHANA, WEST AFRICA
}

\author{
Attipoe Sonny Gad ${ }^{\star}$, Jianmin Cao \\ Department of Management, Faculty of Agricultural Economics and Management, \\ Jilin Agricultural University, Changchun, China \\ Opoku-Kwanowa Yaa \\ College of Resources and Environment Sciences, Jilin Agricultural University, \\ Changchun, China \\ *E-mail: sonnygad49@gmail.com
}

\begin{abstract}
The importance of small-scale maize cultivation to the Ghanaian economy cannot be overemphasized especially in an era where issues of global food security and sustainability are the topmost priorities in developing economies, however, little is known about their profit efficiencies and whatsoever determinants it. This study guided by the above questions adopts the stochastic frontier efficiency approach assuming a Cobb Douglas form. A crosssectional data of 300 small scale maize farmers were obtained by means of structured questionnaires across selected districts in the Brong Ahafo Region. Frontier 4.1 and STATA 14.0 provides the maximum likelihood estimates of the stochastic profit frontier model. Estimated gamma value $(\mathrm{y})$ which measures the level of inefficiency was 0.73 , indicating $73 \%$ variation in maize profit was due to inefficiency in input use and other farm practices, while $27 \%$ of profit deviations from the frontier output came from random factors. Further, empirical results show that farmers in the region had an average profit efficiency of $58 \%$, with estimated minimum and maximum profit efficiency of $19 \%$ and $83 \%$ respectively. This implies that the average maize farmer in the study area gets a nominal profit of about $58 \%$ from their potential output given the current technology available. Practically, it suggests that there is an opportunity to increase profit by $42 \%$. The inefficiency model established that access to credit, farmer education, experience, household size, access to extension and membership of farmer groups increases farmers' profit efficiency, while gender, age, and land tenure system reduce their profit efficiencies.
\end{abstract}

\section{KEY WORDS}

Maize production, profit efficiency, profit frontier analysis, smallholders.

In Ghana, the agricultural sector contributes significantly to economic development, with estimates as high as $28.7 \%$ of GDP in 2010 and $31.1 \%$ in 2018. Among this sector, the crop sector contributes almost $19.5 \%$ of total GDP. The main staple crops and cereals produced in Ghana are plantain, maize, cassava, millet, sorghum, potatoes, and yam. In general, these are produced on a smallholder basis and consumed across the country. Small scale production is estimated to contribute over $85 \%$ of national food production with the majority of these farmers being among the poorest households in Ghana.

Maize is among the major staple crops in Ghana because of its use by almost all regions in the country for preparing different kinds of foods. It is also an essential part of poultry and livestock feed and further used in the brewing industry for the production of beer and other alcoholic beverages. It is an essential traded commodity in West Africa, particularly between Ghana, Nigeria, Burkina Faso, Benin, and Togo mainly through informal trading methods. Maize is grown in the whole of Ghana with an estimated majority of $39 \%$ grown in the Brong Ahafo Region. The leading producing areas are mainly (Brong Ahafo, Eastern and Ashanti regions) where 85 percent of the maize is grown, with the remaining 15 percent 
being cultivated in the northern regions of the country (Northern, Upper East, and Upper West districts).

Currently, the national average maize yield is estimated at 1.61 tonnes per hectare. Adopting improved varieties and technologies, yields of $4-6$ tonnes per hectare have farmers' in demonstration fields. Conversely, lower yields have been attributed to traditional farming practices, the use of low-yielding varieties, lack of credit, bad weather conditions, poor soil fertility, limited use of fertilizers, and inappropriate agronomic practices. Agricultural is a risky venture hence high inputs use does not necessarily result in high returns. However, improvements can be realized by using improved seeds, fertilizers, and modern production practices.

In Africa, where Ghana is not an exception, small scale farmers are constrained with a myriad of problems such as lack of access to production inputs, and efficient produce markets for commercialization purposes. With little or no access to credit from the formal sector, new technologies such as improved seed varieties and agrochemicals have been found to be very expensive by the average small-scale farmers. Practically, it implies that technologies adoption and diffusion rate is low among small-scale farmers, consequently resulting in lower annual yields and minimal incomes. These farmers persist to use traditionally unproductive methods that result in low productivity and high post-harvest losses.

According to Kalarijan (1986), a firm's performance is best judged utilizing the concept of economic efficiency namely technical efficiency and allocative efficiency. A firm is said to be technically efficient when it produces a given output with the minimum possible quantity of inputs. Likewise, Ellis (1988) defines technical efficiency as the ideal level of outputs obtained by applying a given set of inputs, with the availability of a possible range of technologies.

The fundamental benefit of adopting a stochastic frontier is its ability to deal with factors out of the farmer's control and measurement errors and allowing for a statistical test of hypotheses that relate to production structure and degree of inefficiency. Its main weaknesses include the imposing of an explicit parametric form for the underlying technology and further clearly expressed distributional assumption for the inefficiency term.

Researchers Bravo-Ureta and Pinhiero (1993) have stated that most of the studies that have examined efficiency have focused on technical efficiency, understating the importance of technical efficiency, improvement in economic efficiency will lead to greater production efficiency. According to Xu and Jeffrey (1998), studies related to the effects of technical change on efficiency are minimal.

In a production frontier approach, the relationship between inputs and outputs of a production process is described by a production function that establishes the maximum level of output attainable from a given level of input. The Stochastic Production Frontier was independently developed by (Aiger et al., 1977; Meeusen and van den Broeck, 1977).

The estimation methods that exist for efficiency and inefficiency determinations are the maximum likelihood procedure and corrected Ordinary Least Square method. According to Greene (1993), efficiency estimation using OLS results in parameter estimates which are less consistent and efficient compared to maximum likelihood estimates. Since the stochastic frontier model is nonlinear, a nonlinear estimation procedure will suffice better.

The Estimation of the factors that cause inefficiency has generated a lot of debate in frontier studies. The most popular procedure is to first estimate efficiency scores and regress them against a set of firms - specific factors or to use nonparametric or analysis of variance. Kalirajan (1991) and Ray (1988) supported the two-step procedure. This procedure was challenged by other authors and they further concluded that incorporating firm-specific factors in the estimation of the production frontier is best because of their direct impact on efficiency (Kumbhakar et al.1991; Battese and Coelli,1995). According to Reifschneider and Stevenson (1991), it was best to express the inefficiency effects as a function of a variable vector and a random deviation, and further estimation of all the parameters in a single-stage maximum-likelihood procedure. Alternatively, Coelli (1995) presents a model in which the technical inefficiency effects are specified to be a function of some firm-specific factors together with their correlation with the input variables of a production frontier. 
In this study, profit analysis of smallholder maize producers in the Brong Ahafo region of Ghana is made, specifically, the factors that contribute immensely to profit efficiency is hitched on and those that reduce efficiency is targeted and appropriate recommendations are given. The study is relevant in the sense that small scale maize production in the region has been in existence for quite a number of years but no special measures have been taken to help improve farmers' profit-making ability. Consequently, with an in-depth analysis of such factors, the Ministry of Food and Agriculture and relevant development partners can target best practices that will increase their profit-making ability and consequently alleviating poverty that is pervasive among small scale farmers.

\section{METHODS OF RESEARCH}

The study is based on farm-level data of small scale maize farmers in the Brong-Ahafo Region. The study uses cross-sectional data from both the major and minor production seasons. Major season maize cultivation occurs from March to June and minor season from mid-August to November. Nkoranza, Kintampo North and South, Wenchi Districts are in the transition zone where soils are deep and well-drained. Major districts such as Sunyani West and Berekum occur in the semi-deciduous forest zone which satisfies the weather requirements for maize production. The average annual rainfall and temperature in the region are $1,300 \mathrm{~mm}$ and $270^{\circ} \mathrm{C}$ respectively. Agriculture is the main source of livelihood strategy for people in this area. The staple crops grown include plantain, maize, yams, cassava, and cocoyam. The majority of farm sizes are on a small scale basis. Small scale farmers were sampled through a multistage sampling approach defined by the two zones in the region. Three major maize producing districts were purposively chosen from each zone, after which two communities from each district were randomly selected. 25 small-scale maize farmers were randomly selected from each community giving a total of 300 farmers. Primary data was collected using structured questionnaires and analyzed using descriptive statistics and stochastic profit frontier models.

The stochastic frontier method of analyzing efficiency proposed by Aiger et al., (1977) and Meeusen and van den Broeck (1977) was adopted for this study. The method allows for the sensitivity of data to random shocks by including a conventional random error term in the estimation of the profit frontier such that only deviations caused by controllable decisions are attributed to inefficiency. The maize farmers' inefficiency is assumed to be part of the error term consisting of two parts-a random error term which is normally distribution $N\left(0, \sigma^{2}\right)$ and represents random shocks and measurement errors, and the inefficiency term which is onesided (non-negative). The inefficiency error term is assumed to have a half-normal distribution in this study. The profit frontier is expressed as:

$$
Y_{i}=f\left(X_{i}, \beta\right)+\varepsilon_{i} ; \text { and } \varepsilon_{i}=\left(V_{i}-U_{i}\right)(1)
$$

After taking natural logarithm, the above equation becomes:

$$
\operatorname{In} Y_{i}=\operatorname{Inf}\left(X_{i}, \beta\right)+\left(V_{i}-U_{i}\right)(2)
$$

Where $Y_{i}$ is the output level; $f\left(X_{i}, \beta\right)$ is a suitable function such as Cobb-Douglas production functions, $X_{i}$ is a vector of the transformation of inputs and $\beta$ is a vector of unknown parameters. According to Battese and Coelli (1995), the error term $V_{i}$ is the random error term and is assumed to be iid. $N\left(0, \sigma v^{2}\right)$ and independent of $U_{i}$, while $U_{i}$ accounts for deviation because of inefficiency effects and are independently distributed and truncated at zero of the $\mathrm{N}\left(\mathrm{U}_{\mathrm{i}}, \sigma \mathrm{u}^{2}\right)$ distributions.

The stochastic frontier analysis approach specifies the profit efficiency of an individual farm as the ratio of the observed output to the corresponding frontier output based on the level of inputs used. Thus, profit inefficiency is defined as the level by which profit from the farm is less than the frontier profit. Profit efficiency (PE) can be specified as: 


$$
P E_{i}=\frac{y_{i}}{y_{i}^{*}}=\frac{\exp \left(x_{i} \beta+V_{i}-U_{i}\right)}{\exp \left(x_{i} \beta+V_{i}\right)}=\exp \left(-U_{i}\right)
$$

Where $Y_{i}$ is the observed profit/output and $Y_{i}^{*}$ is the frontier profit/output. The profit efficiency $\left(P E_{i}\right)$ value lies between 0 and 1.

Small-scale maize farmers' profit efficiency is defined as profit gained from operating on the profit frontier, thus taking into consideration farm-specific prices and other external factors. Considering a maize farm that maximizes profit in relative perfectly competitive input and output markets, a Cobb-Douglas functional form for the small-scale farmers is fitted and specified as follows:

$$
\operatorname{In} Y=\operatorname{In} \beta_{0}+\beta_{1} \operatorname{In} X_{1}+\beta_{2} \operatorname{In} X_{2}+\beta_{3} \operatorname{In} X_{3}+\beta_{4} \operatorname{In} X_{4}+\beta_{5} \operatorname{In} X_{5}+\beta_{6} \operatorname{In} X_{6}+\beta_{7} \operatorname{In} X_{7}+\varepsilon_{i}
$$

Where: $\ln Y$ is the total profit less variable cost, $\beta_{1}$ is labor cost per day, $\beta_{2}$ is farm size, $\beta_{3}$ is value of fertilizer, $\beta_{4}$ is the price of seeds, $\beta_{5}$ is the price of farm tools, $\beta_{6}$ is the value of herbicide and pesticides, $\beta_{7}$ is the average price for spraying.

The inefficiency model is defined as:

$$
U_{i}=\delta_{0}+\delta_{1} X_{1}+\delta_{2} X_{2}+\delta_{3} X_{3}+\delta_{4} X_{4}+\delta_{5} X_{5}+\delta_{6} X_{6}+\delta_{7} X_{7}+\delta_{8} X_{8}+\delta_{8} X_{8}+\varepsilon_{i}
$$

Where: $\delta_{1}$ to $\delta_{6}$ represents possible socio-economic variables such as access to credit, age, education, farming experience, household size, member of FBO, gender, land tenure and access to the extension. They are perceived to have a possible influence on the profit efficiency of the selected maize farmers. The variance of the random errors is represented as $\sigma^{2} v$ and that of the profit inefficiency effect represented as $\sigma^{2} u$ and finally, the overall variance of the model is $\sigma^{2}$ and represented as:

$$
\sigma^{2}=\sigma_{u}^{2}+\sigma_{v}^{2}(6)
$$

This determines the total variation of farmers' profit from the frontier which is due to inefficiency. The estimate of gamma is $\gamma=\sigma_{u}^{2} / \sigma^{2}$, which represents the share of inefficiency in the overall residual variance with values between 0 and 1 . If $y=0$, inefficiency is absent and deviation from the frontier is entirely due to random noise, hence OLS estimation becomes favorable, if $\mathrm{Y}=1$, it indicates that the deviation is entirely due to inefficiency, if $(0 \leq y \leq 1)$ then deviations are as a result of both inefficiency and random factors. The parameters of eq. (4) were estimated using the maximum likelihood estimate (MLE) method, following estimation by Battese and Corra (1977). Frontier 4.1 and STATA 14.0 provides the maximum likelihood estimates of the stochastic profit frontier model and estimates of $\beta$ and $\gamma$.

\section{RESULTS AND DISCUSSION}

Table 1 shows the demographic characteristics of the selected farmers. A total of $90 \%$ of the respondents were males while $30 \%$ were females implying that maize farming in the study area is male-dominated. A majority (63.3\%) of the farmers were aged between $20-40$ years while $16.7 \%$ were aged between $41-60$ years. In terms of education, a majority $(43.3 \%)$ of farmers had no formal education, $36.7 \%$ had primary/junior high school level, $19.3 \%$ had secondary education and $0.7 \%$ tertiary education. Moreover, the study reveals that $73.4 \%$ of farmers were cultivating farm sizes between 1-3 hectares, while $23.3 \%$ cultivating between 4-7 hectares and only 3.3\% cultivating more than 8 hectares. The results align with the findings of Bidzakin et al., (2014) who reported that about $60 \%$ of small-scale maize farmers in Ghana have farm sizes between 1-3 hectares. However, $62.6 \%$ of farmers own their farms while $73.3 \%$ were unable to secure rural credit for farming purposes. The limited number of agricultural extension officers in the region further place a great burden on farming technology information dissemination. It was further discovered that the majority of 
the farmers had farming experience between the 21-30 years, which was plausible to conclude that such farmers are well vested in the farming business. Another poignant observation that emerged from the study was due to the fact that $84.7 \%$ of the small-scale farmers had alternative sources of income, thus they are involved in other jobs apart from maize cultivation. Finally, majority $(70 \%)$ of the farmers were active members of farmerbased organizations either at the community level or district level.

Table 1 - Characteristics of maize farming household respondents

\begin{tabular}{|c|c|c|c|}
\hline Variables & Category & $\begin{array}{c}\text { Frequency } \\
(\mathrm{N}=300)\end{array}$ & $\begin{array}{c}\text { Total } \\
(\%)\end{array}$ \\
\hline Gender & Male & 270 & 90.0 \\
& Female & 30 & 10.0 \\
\hline \multirow{3}{*}{ Age of Farmer (years) } & $20-40$ & 190 & 63.3 \\
& $41-60$ & 50 & 16.7 \\
& $>60$ & 60 & 20.0 \\
\hline \multirow{3}{*}{ Formal Educational } & None & 130 & 43.3 \\
& Primary/Junior & 110 & 36.7 \\
& Secondary & 58 & 19.3 \\
& Tertiary & 2 & 0.7 \\
\hline \multirow{2}{*}{ Farm Size (Hectares) } & $1-3$ & 220 & 73.4 \\
& $4-7$ & 70 & 23.3 \\
& $>8$ & 10 & 3.3 \\
\hline \multirow{2}{*}{ Tenure System } & Own farm & 280 & 93.3 \\
& Family farm & 18 & 6.0 \\
& Sharecropper & 2 & 0.7 \\
\hline Access to Credits & No & 220 & 73.3 \\
& Yes & 80 & 26.7 \\
\hline Access to Extension Services & No & 189 & 63.0 \\
& Yes & 111 & 37.0 \\
\hline & $1-10$ & 18 & 6.0 \\
& $11-20$ & 113 & 37.7 \\
& $21-30$ & 125 & 41.7 \\
& $>30$ & 44 & 14.6 \\
\hline \multirow{2}{*}{ Farming Experience (years) } & No & 46 & 15.3 \\
& Yes & 254 & 84.7 \\
\hline Livelihood Diversified (off-farm income) & No & 210 & 70.0 \\
& 90 & 30.0 \\
\hline Member of FBO & & & \\
\hline
\end{tabular}

Farm specific variables. A summary statistic of key variables used in the stochastic frontier model is represented in Table 2. Estimated results from the data analysis show that the mean yield of $620 \mathrm{~kg} / \mathrm{ha}$ of shelled bagged maize was recorded over the sample area with a standard deviation of $17.7 \mathrm{~kg} / \mathrm{ha}$. This practically gives a coefficient of variability to $23 \%$. This variability reveals that farmers recorded an average yield that varied widely from that recorded in most parts of Ghana. Furthermore, empirical results from previous studies reveal that this value is lower than the projected 1.7 million tons/ha for Ghana. Moreover, an average of $\mathrm{GH} \phi 3.158$ per $\mathrm{kg}$ of maize was recorded in the sampled area as price of output. The mean gross margin of $\mathrm{GH} \phi 1500.00$, a minimum gross margin of $\mathrm{GH} \phi 54.00$, a maximum gross margin of $\mathrm{GH} \phi 3,234.00$ were obtained. This difference indicates that farmers cultivate different sizes of farmland with the majority of the maize farmers having average gross margin very close to that recorded in the sample area. The value of seed used for the production year ranges between $\mathrm{GH} \phi 1.3$ to 3.3 per $\mathrm{kg}$ with a mean of $\mathrm{GH} \phi 2.7$ and standard deviation of 0.23 . The mean labor value of $\mathrm{GH} \phi 38.1$ in man-days is applied, while the farmers apply average herbicide and pesticide value of $\mathrm{GH} \phi 25.5$. The mean cost of intermediate input per $\mathrm{kg}$ was $\mathrm{GH} \phi 31.5$. The average cost of farm tools was $\mathrm{GH} \phi 24000$. This unexpected high figure was due to the purchase of expensive farming equipment such as maize shellers, plough, mini planting machines, mini harvesting machines, and tricycles.

Maize stochastic profit functional analysis. The estimation of the stochastic profit frontier model is presented in Table 3 . It was discovered that the inefficiency component of the disturbance term $\left(\mathrm{U}_{\mathrm{i}}\right)$ is significantly different from zero as indicated by the significant log- 
likelihood ratio test (LR test) of 75.34 assuming a chi-square distribution, hence the null hypothesis of no technical inefficiency in profit $\left(\mathrm{H}_{0}: \mathrm{U}_{\mathrm{i}}=0\right)$ among maize farmers is rejected. The estimated sigma-squared $\left(\sigma^{2}\right)$ value of 0.313 indicates a "good fit" and the appropriateness of the specified distributional assumption of the composite error term rather than the average response specification. The Gamma $(\mathrm{Y})$ measures the level of inefficiency in the variance parameter and determines if a stochastic frontier analysis is appropriate.

Table 2 - Statistics of variables for the estimation of the stochastic profit frontier model

\begin{tabular}{|c|c|c|c|c|}
\hline Variables & Minimum & Maximum & Mean & Std. dev. \\
\hline Gross Profit $(\mathrm{GH} \phi)$ & 54.0 & $3,234.0$ & 1500.0 & 321.3 \\
\hline Farm size (ha) & 1.2 & 8.1 & 4.5 & 1.70 \\
\hline Farm Yield kg/ha & 357 & 712 & 620 & 17.7 \\
\hline Labor units/ man day $(\mathrm{GH} \phi)$ & 15.3 & 50.8 & 38.1 & 10.3 \\
\hline Price of fertilizer per kg (GH $\phi)$ & 21.2 & 38.7 & 31.5 & 7.4 \\
\hline Price for herbicide and Pesticide $(\mathrm{GH} \phi)$ & 17.3 & 39.3 & 24.5 & 5.3 \\
\hline Price for spraying (GH $\phi)$ & 27.3 & 57.4 & 45.3 & 5.6 \\
\hline Price of seeds per kg (GH $\phi)$ & 1.3 & 3.3 & 2.7 & 0.2 \\
\hline Cost of farm tools $(\mathrm{GH} \phi)$ & 39.4 & $24,000.0$ & $13,000.0$ & 1200.4 \\
\hline
\end{tabular}

Table 3 - The maximum likelihood estimate of the stochastic profit frontier model

\begin{tabular}{|c|c|c|c|}
\hline Variable & Coefficient & Std. Error & t-statistics \\
\hline Constant & 3.897 & 0.557 & 3.770 \\
\hline Farm Size (ha) & 0.391 & 0.057 & 2.196 \\
\hline Price of seeds per kg $(\mathrm{GH} \phi)$ & 0.374 & 0.167 & 1.978 \\
\hline Farm Yield kg/ha & 0.816 & 0.678 & 2.174 \\
\hline Labor units/ man day $(\mathrm{GH} \phi)$ & -0.788 & 0.098 & -1.972 \\
\hline Price of fertilizer per kg $(\mathrm{GH} \phi)$ & 0.640 & 0.256 & 3.175 \\
\hline Price for herbicide and Pesticide $(\mathrm{GH} \phi)$ & -0.649 & 0.118 & -0.773 \\
\hline Price for spraying $(\mathrm{GH} \phi)$ & 1.178 & 0.675 & 1.322 \\
\hline Cost of farm tools $(\mathrm{GH} \phi)$ & -0.227 & 0.345 & -0.174 \\
\hline Variance Parameters & & & \\
\hline Sigma U-squared $\left(\sigma^{2}\right)$ & 0.227 & & \\
\hline Sigma V-squared $\left(\sigma^{2}\right)$ & 0.134 & & \\
\hline Lamda $(\lambda)$ & 1.072 & & \\
\hline Sigma-squared $\left(\sigma^{2}\right)$ & 0.313 & & \\
\hline Gamma $(\gamma)$ & 0.734 & & \\
\hline Log-Likelihood Function & -212.451 & & \\
\hline LR test & 75.342 & & \\
\hline
\end{tabular}

***, **, * significance at 1, 5, 10\% significance level, respectively.

The estimated gamma value of 0.73 indicates that $73 \%$ variation in the maize profit was due to inefficiency in input use and other farm practices, $27 \%$ of the deviations of the actual profit from the frontier output came from random factors. This suggests that technical inefficiency has a fundamental role in explaining profit levels among small-scale maize farmers in the region. Based on the assumptions of a competitive market, apart from the cost of farm tools, pesticides, and labor, the estimated coefficients of the parameters of the profit function are positive. These negative coefficients could be due to the current inflation rate, armyworm epidemic, and labor-intensive mature of maize production. The other variables in the normalized profit model which have a positive coefficient, suggest that as these variables (seed cost, farm size, fertilizer cost, spraying cost) increase, the normalized profit of the farmer's increases, while the variables with negative coefficient decrease the normalized profit of farmers. These findings are consistent with the results of similar studies conducted in Ghana (De Groote, 2002; Tefera, 2012; Wegary et al., 2004; Shiferaw et al., 2011).

Determinants of profit efficiency of farmers. The sources of variation in profit efficiency estimates are presented in Table 4. The variables used in the profit inefficiency model are the determinants of profit inefficiency rather than efficiency. It implies that a positively signed variable reduces the profit efficiency level while a negatively signed variable increases the profit efficiency level of the maize farmers. The variables in the inefficiency model with a 
negative coefficient, suggesting as these variables (membership of FBO, education, experience, access to credit and household size) increases, the profit efficiency of farmers also increases, hence increase in profit. The variables (gender, age, access to extension, land tenure) are positive suggesting the decrease in profit efficiency of the maize farmers. The positively signed coefficient of gender suggests that males are often endowed with resources such as land and farming equipment by inheritance system, hence the absence of such resource makes venturing into farming very difficult, these findings support the work of Bafffoe-Asare et al., (2013) and Anang et al., (2011).

Table 4 - Determinants of profit efficiency of maize farmers

\begin{tabular}{|c|c|c|c|}
\hline Variable & Coefficient & Standard Error & t-statistics \\
\hline Constant & 4.573 & 0.874 & 4.407 \\
\hline Gender & 0.018 & 0.003 & 0.371 \\
\hline Age & 0.079 & 0.032 & 0.217 \\
\hline Education & -0.432 & 0.411 & -1.337 \\
\hline Experience & -0.421 & 0.041 & -2.731 \\
\hline Access to credit & -0.178 & 0.397 & -1.873 \\
\hline Access to extension & 0.694 & 0.032 & 2.241 \\
\hline Household Size & -0.194 & 0.006 & -1.327 \\
\hline Land tenure & 0.017 & 0.003 & 0.371 \\
\hline Member of FBO & -0.321 & 0.131 & -1.378 \\
\hline
\end{tabular}

${ }^{* * *},{ }^{* *},{ }^{*}$ significance at $1,5,10 \%$ significance level, respectively.

The age of farmers practically influences their profit-making ability, as older farmers tend to have less strength and time for their farm as a result of sickness and other domestic issues (Mumuni and Oladele, 2016). Access to extension service was significant but positively signed which suggests that agricultural extension services in the area need to be harnessed towards maize production. The negative coefficient of education suggests that farmers who have gained formal education can critically analyze and make decisions between technologies (Ente and Igbokwe, 2009).

Table 5 - Distribution of maize farmers' profit efficiencies

\begin{tabular}{|c|c|c|}
\hline Efficiency score (\%) & Frequency & Relative frequency (\%) \\
\hline $0.10-0.20$ & 5 & 1.7 \\
\hline $0.20-0.30$ & 11 & 3.7 \\
\hline $0.30-0.40$ & 21 & 7 \\
\hline $0.40-0.50$ & 39 & 13 \\
\hline $0.50-0.60$ & 140 & 13.6 \\
\hline $0.60-0.70$ & 39 & 11.7 \\
\hline $0.70-0.80$ & 35 & 3.3 \\
\hline $0.80-0.90$ & 10 & 0 \\
\hline $0.90-1.00$ & 0 & 100.0 \\
\hline Total & 300 & \\
\hline Minimum & 0.19 & \\
\hline Maximum & 0.83 & \\
\hline Mean & 0.58 &
\end{tabular}

Apart from influence education has on technology adaption, educated farmers are able to keep adequate farm records and participate in market commercialization which will help increase their profit in the long run. Access to secure and reliable institutional credit by small scale maize farmers in the district is constraint by a myriad of problems. Evidently, the presence of rural and community banks in the selected districts are tasked with supplying farming credit for these small-scale farmers. Studies by Abdul-Baaki et al., (2013) concluded that farmers with access to credit are able to invest more on their farm which automatically translates into increased productivity and higher profit returns from the sales of produce. Household size was significant suggesting that farmers with larger households are able to cultivate larger hectares at a reduced labor cost. Finally, being a member of farmer-based 
organization comes with special benefits such as group credit, participating in training programs, access to fertilizer and other subsidies and sharing of tractors, harvesters, and ploughs. It is relevant to stress that for small scale farmers to operate with minimal inefficiency, the factors which contribute positively to maize productivity and profit efficiency should be given urgent attention by the Government of Ghana and other relevant Agricultural Development Partners.

Farmers Profit Efficiency Distribution. Presented in Table 5 is the output from Frontier 4.1 software which accurately provides considerable variation of profit efficiency index scores. The fact that profit efficiencies of sampled maize farmers were less than 1 implies that no farm reached the maize profit possibility frontier.The predicted farm overall profit efficiency levels ranged between 0.19 and 0.83 , with an overall mean profit efficiency of 0.58 . This implies that the average maize farmer in the study area gets a nominal profit of about $58 \%$ from their potential output given the current technology available. That is, small-scale farmers in the study area produce at a mean profit level below $42 \%$ of the profit frontier output. Thus, in the long run, there is a scope for increasing profit by adopting new technologies, practices and efficient combination and allocation of production factors. From table 5, it is evident that majority (46.65\%) farmers were operating within $0.50-0.60$ profit efficiency zone. This suggests that farmers used for this study were efficient in allocating their cost structure in course of maize production. Since profit efficiency was positively influenced by these variables; education, access to credit, experience, membership of farmer-based organization, effective agricultural policy formulations by the Ghana government should be consistent and geared towards sustainability and profit realization among small-scale maize farmers.

\section{CONCLUSION}

The results of this study clearly show that employing the stochastic profit frontier assuming a Cobb Douglas functional form was adequate in assessing the determinants of profit efficiencies and its variations among small-scale maize farmers in the sample area. The profit efficiency distributions have shown that maize farmers in the region are reasonably efficient in their resource allocations as they are operating at a nominal profit of about $58 \%$ from their potential output given the current technology available. Moreover, the estimated gamma value of 0.73 indicates that $73 \%$ variation in the maize profit was due to inefficiency in input use and other farm practices, while $27 \%$ of the deviations of the actual profit from the frontier output came from random factors. The majority $(46.65 \%)$ of farmers were operating within $0.50-0.60$ profit efficiency zone suggesting that a need for more room for improvement with respect to their current methods of production. This study has some important policy implications; first, government investment in rural agriculture is needed for increased maize productivity in the region. Secondly, investment in rural infrastructures such as good roads, schools, and markets are the facets of agriculture development in all parts of the world. Thirdly, direct subsidies for small-scale maize farmers on production inputs such as fertilizers, pesticides, and herbicides should be encouraged. Finally, since the inefficiency associated with controllable decisions is about $73 \%$, government through the Ministry of Food and Agriculture should intensify agriculture extension service delivery throughout the region.

\section{CONFLICT OF INTERESTS}

Authors clearly declare that they have no competing interests.

\section{ACKNOWLEDGEMENTS}

This research was conducted while Mr. Gilbert Kwaku Baah was the Bodi District Director of Agriculture, working on Planting for Food and Jobs Project sponsored by the Canadian Government, and initiated by the Ministry of Food and Agriculture, Ghana. We appreciate the support of all staff and extension agents from the Ministry of Food and Agriculture for the active involvement in questionnaire design and data collection. 


\section{REFERENCES}

1. Abdul-Baaki YK, Alhassan B and Bashiru S, (2013). Assessing Rural Banks Effectiveness in Ghana. Int. Bus. Res. 6(3):140-153.

2. Aigner DJ, Lovell CA and Schmidt P, (1977). Formulation and estimation of stochastic frontier production function model. J. Econom.1:21-37.

3. Anang BT, (2011). Farmers's management practices and the quality of cocoa beans in Upper Denkyira District of Ghana. Asian J. Agric. Sci. 3:487-491.

4. Baffoe-Asare R, Danquah JA and Annor-Frempong F, (2013). Socioeconomic factors influencing adoption of CODAPEC and cocoa high-tech technologies among smallholder farmers in Central Region of Ghana. Amer. J. Exp. Agric. 3:277-292.

5. Battese GE and Coelli TJ, (1995). A model for technical inefficiency effect in stochastic frontier production for panel data. Empir. Econ. 20: 325-345.

6. Battese GE and Corra GS, (1977). Estimation of a production frontier model: with application to the pastoral zone of Eastern Australia. Aust. J. Agric. Econ. 21:169-179.

7. Bidzakin JK, Fialor SC and Asuming-Brempong D, (2014). Small scale maize production in Northern Ghana: stochastic profit frontier analysis. ARPN. J. Agric. Bio. Sci. 9(2):76-83.

8. Bravo-Ureta BE, (1993). Efficiency analysis of developing country agriculture: a review of the frontier function literature. Agric. Resour. Econ. Rev. 22(1): 88-101.

9. Coelli TJ, 1995. Recent development in frontier modelling and efficiency measurement. Aust. J. Agric. Econ. 39:219-245.

10. De Groote H, (2002). Maize yield losses from stem borers in Kenya. Insect Sci. Appl. 22: 89-96.

11. Ellis H, 1988. Cost and profit efficiency in European Banks. J. of Int. Financial Mark. Inst. Money. 12: 33-58.

12. Enete AA and Igbokwe EM, (2009). Cassava market participation decisions of producing households in Africa. Tropicultura. 27(3):129-136.

13. Green W, (1993). The econometric approach to efficiency analysis. In: Fried HO, Lovell CAK, Schmidt SS (eds), the measurement of productive efficiency: techniques and applications. Oxford University Press, pp 68-119.

14. Kalirajan K, (1986). Measuring technical efficiencies from interdependent multiple outputs frontiers. J. Quant. Econ. 2:263-274.

15. Kalirajan K, (1991). The importance of efficient use in the adoption of technology: a micro panel data analysis. J. Prod. Anal. 2:113-126.

16. Kumbhakar SC, Ghosh S and McGuckin J, (1991). A generalized production frontier approach for estimating determinants of inefficiency in U.S. dairy farms. J. Bus. Econ. Stat. 9:279-286.

17. Meeusen W and Van den Broeck J, (1977). Efficiency estimation from Cobb-Douglas production functions with composed error. Int. Econ. Rev. 18:435-443.

18. Mumuni E and Oladele OI, (2016). Access to livelihood capitals and propensity for entrepreneurship amongst Rice farmers in Ghana. Agric. Food Secur. 5 (1):1-11.

19. Ray SC, (1988). Data envelopment analysis, nondiscretionary inputs and efficiency: an alternative interpretation. Socio-Econ. Plan. Sci. 22(4):167-176.

20. Reifschneider D and Stevenson R, (1991). Systematic departures from the frontier: a framework for the analysis of firm inefficiency. Int. Econ. Rev. 32(3): 715-23.

21. Shiferaw B, Prasanna BM, Hellin J and Bänzigern M, (2011). Crops that feed the world. Past successes and future challenges to the role played by maize in global food security. Food Secur. 3: 307.

22. Tefera T, (2012). Post-harvest losses in African maize in the face of increasing food shortage. J. Food Secur. 4: 267-277.

23. Wegary D, Kitaw D and Demissie G, (2004). Assessment of losses in yield and yield components of maize varieties due to grey leaf spot. Pest Mgt. J. Ethiopia. 8: 59-69.

24. Xu Y and Jeffrey S, (1998). Technical efficiency of rice farms in Thailand; a nonparametric approach. In Proceedings, 2003 Hawaii International Conference on Business, Honolulu, June, pp 18-21. 